\title{
DIFFERENCE IN TRAINING LOAD AND TECHNICAL ACTIONS DURING SMALL-SIDED GAMES IN JUNIOR AND SENIOR SOCCER PLAYERS
}

original paper

doi: https://doi.org/10.5114/hm.2017.73623

\author{
LIANNE LANGENDAM ${ }^{1}$, CORNELIS M.I. (NIELS) VAN DER LINDEN², \\ FILIPE MANUEL CLEMENTE ${ }^{3,4}$ \\ ${ }^{1}$ Faculty of Behavioural and Movement Sciences, Free University of Amsterdam, Amsterdam, The Netherlands \\ 2 JOHAN Sports: Performance Analytics for Sports Teams, Noordwijk, The Netherlands \\ ${ }^{3}$ School of Sport and Leisure, Polytechnic Institute of Viana do Castelo, Melgaço, Portugal \\ ${ }^{4}$ Instituto de Telecomunicações, Delegação da Covilhã, Covilhã, Portugal
}

\begin{abstract}
Purpose. The aim of the study was to analyse the differences in junior and senior soccer players during small-sided games (SSGs). Physiological responses (heart rate, rating of perceived exertion [RPE]), time-motion variables (acceleration sum, distance covered), and technical actions (dribbles, passes, tackles, interceptions, shots) were measured and compared between the different age groups and across the games.

Methods. The total of 14 junior players (aged $17.6 \pm 0.5$ years) and 11 senior players (18.7 \pm 1.1 years) participated in the study. All participants performed $4 \times 4$-minute 5 versus 5 SSGs with 1 -minute passive rest and 1-minute active rest. Goalkeepers and coach encouragement were included.

Results. No differences in physiological responses or time-motion variables were found between junior and senior players. Physiological responses did not change across the games except for the $\operatorname{RPE}(\mathrm{F}(3,51)=26.57, p<0.001)$, which increased with fatigue. The number of technical actions was the same for junior and senior players and did not change across the games. Additionally, a high correlation was found between acceleration sum and total distance $(r=0.81)$.

Conclusions. It was concluded that no differences existed in physiological responses or technical actions between junior and senior players for this specific soccer club.
\end{abstract}

Key words: soccer, physiological responses, training load, small-sided games, time-motion variables

\section{INTRODUCTION}

A lot of research focuses on measuring training and match intensity in soccer [1-3]. The outcome of this research is expressed in external and internal training load [4]. The external training load (movement-based) prescribed by the trainer might be the same for all players, but the internal training load (perception of effort) will be different for every individual player. A simple and quick method to quantify the internal training load is with the rating of perceived exertion (RPE). This method uses a 1-10 or 6-20 scale to identify how hard the training was. It takes also sleep, stress, and weather conditions into account because these parameters affect the level of energy [3]. The approach is reliable and constitutes a good indicator of global internal comparing [3]. That is why athletes can rate the same training differently owing to a different physiological and psychological state.

Another parameter that can be measured is heart rate, which gives information about the cardiorespiratory status of the player [5, 6]. Heart rate increases in a linear way with the oxygen uptake but there are a couple of factors that influence the heart rate, like body temperature, hydration, sleep, stress, illness, and medication. In some research, the outcome measures are represented as a percentage of the maximum heart rate $\left(\mathrm{HR}_{\max }\right)$, heart rate variability, or the heart

Correspondence address: Lianne Langendam, JOHAN Sports, Kapteynstraat 1, 2201 BB, Noordwijk, The Netherlands, e-mail: Lianne_langendam@icloud.com

Received: December 1, 2017

Accepted for publication: January 31, 2018

Citation: Langendam L, van der Linden CMI, Clemente FM. Difference in training load and technical actions during small-sided games in junior and senior soccer players. Hum Mov. 2017;18(5)special/issue:146-156 doi: https://doi.org/10.5114/ hm.2017.73623. 
rate recovery [6]. Time in seconds above $90 \%$ of $\mathrm{HR}_{\max }$ $\left(\mathrm{HR}_{\max } 90\right)$ is also a valuable parameter; it remains above the anaerobic threshold and is often used in training to increase maximal oxygen uptake [7]. In this research, the percentage of $\mathrm{HR}_{\max }$, the time above $\mathrm{HR}_{\max } 90$, and heart rate recovery will be investigated.

A great deal of research has been conducted on measuring training intensity with GPS and accelerometers $[4,8]$. Different parameters can be derived from GPS [9]: total distance, average running speed, and distance covered at high velocities. A triaxial accelerometer can measure accelerations and decelerations in three orthogonal directions. Another way to display training intensity is with acceleration sum (overall measure of load), which can be calculated from triaxial accelerometer data and has a strong correlation with the total distance $[8,10]$.

Few experiments have been carried out to discover the difference in training intensity and recovery between junior and senior soccer players. Dellal et al. [11] and Stevens et al. [12] compared time-motion variables between different groups; these included senior, youth, and amateur players. Dellal et al. [11] found that professionals covered more distance in sprinting, independently of the number of ball touches. Stevens et al. [12] observed no differences between professional senior and professional youth players. This may be due to the ceiling effect in small-sided games (SSGs) for fit players. Technical or tactical constraints can reduce the training intensity for fit players. Exercise intensity could be increased when the pitch area per player is enlarged; this could reveal any differences between age groups $[2,13]$. There may also be differences in the recovery or the technical abilities of players from different groups. Until this moment, no difference has been found between age groups. Differences in physiological responses and time-motion variables may depend on the club and the playing level. Besides, there are a limited number of studies examining the age difference in soccer. Therefore, this research will focus on investigating the differences in physiological responses and time-motion variables between junior and senior players.

Commonly used training forms are SSGs, where two teams of less than 11 people play on a smaller pitch size. SSGs are used during training to increase anaerobic condition and at the same time improve tactical and technical abilities [14]. A lot of research has already been done on different factors influencing physiological responses in SSGs [15, 16]. Changing the rules of the game influences the intensity and technical demands of the training. Köklü et al. [17] show that with a decreasing number of players, the intensity of the game increases. Others prove that a medium pitch size $(30 \times 40 \mathrm{~m})$ requests high physical demands with a large number of technical actions in a 5 vs. 5 SSG $[18,19]$. Dellal et al. [14] indicate that the heart rate response is higher with the presence of a goalkeeper; this may be due to more motivation to score and protect the own goalkeeper. Other research has also shown that the influence of coach encouragement is important to increase the intensity of the game [16].

The comparison between bouts is also an interesting parameter for coaches to determine the physiological status of the players. In previous research, it was found that both heart rate and RPE increased along the bouts [20]. Therefore, a comparison between training bouts will also be included in this research.

The current knowledge regarding the training intensity and recovery in different age groups is minimal. The training intensity and recovery of the players is an important aspect for coaches to develop new training programs. Previous research was limited by the small size of the field and the restriction on the number of ball touches $[11,12]$. It is difficult to make long sprints in a small pitch, which could decrease the training intensity for fit players. Besides, a reduction in the number of ball touches could influence the training intensity and percentage of successful passes. When the number of ball touches is reduced, the running distance increases, but the percentage of successful passes decreases. The SSG would be more similar to a real match without restrictions. Thus, it could be interesting to examine the difference in training load and recovery with a larger pitch size and without limitation on the number of ball touches.

Therefore, this research will focus on physiological responses (heart rate, RPE), time-motion variables (acceleration sum, distance covered), and technical actions (dribble, interception, pass, shot, tackle) across SSGs in junior and senior soccer players on a medium pitch size with goalkeepers and coach encouragement. We expect the physiological responses and time-motion variables to be higher for senior players. Thereby, we await the acceleration sum and RPE to stay the same along the bouts. The heart rate recovery will be steady across the games for the fit players, with the same acceleration sum and distance covered. Finally, we expect the number of technical actions and the percentage of successful actions to be higher in senior players. 
L. Langendam, CMI (Niels) van der Linden, FM Clemente, Difference between age groups in soccer

\section{MATERIAL AND METHODS}

\section{Participants}

The total of 14 junior soccer players $(17.6 \pm 0.5$ years) and 11 senior soccer players $(18.7 \pm 1.1$ years $)$ participated in the study. The criteria used to split the players into 2 groups were a combination of age, different coach, and competition level. The anthropometric characteristics of the players are shown in Table 1. Both teams were part of the same Dutch soccer club (juniors playing in the First Division for junior players and seniors playing in the Third Division) and none of the players had an injury within the study period. Although the junior players had more experience at the current club, the senior players were more experienced at different clubs. The $\mathrm{HR}_{\max }$ recorded in the last interval shuttle run test in January 2017 ( 2 months before the first test day) was used to calculate the time spent above $\mathrm{HR}_{\max } 90$. Both junior and senior players had 6-8 training sessions per week and each session lasted for 1-1.5 hours. The keepers were excluded from the results because their physical activity and technical actions were different from those of the players in the field [21]. All players provided their written informed consent after an explanation of the experimental procedure. When the players were under 18 years of age, the informed consent was obtained from the parent or guardian. The players had the opportunity to withdraw from the study at any time without explanation. The study followed the ethical standards of the Declaration of Helsinki for experiments conducted in humans.

\section{Experimental design}

The experiments were divided over 2 days, within a period of 7 weeks. The measurements were performed on regular training days and all players were familiar with SSGs and the Borg CR10 scale. The experiment took place at least 3 days after a match and both test days occurred on the same day of a week.

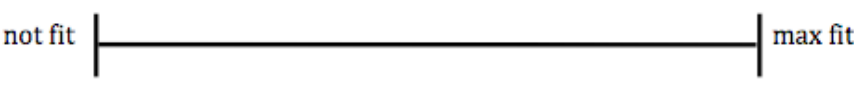

Figure 1. Visual analogue scale score: from 'not fit to play at all' to ' $100 \%$ fit to play'

Before the training, all players were asked to fill in a visual analogue scale (VAS) with the aim to check their physiological and psychological status (Figure 1). The players had to mark the line at the point corresponding to how fit they were at that moment. The test started after a 10-minute general warm-up, which was the same for both groups. The same coach conducted the warm-up before the test and encouraged both teams on both testing days. The coach divided all the junior players into 2 teams of 5 players, including 1 goalkeeper, and did the same with the senior players. All participants played within the same age group, so the junior players competed only against junior players. Each athlete was placed in a position close to their real position on the field, which ensured that both teams were of equal strength.

\section{Equipment}

During the test, all players wore a heart rate band around the chest (Polar, Team2 Pro) and a time-motion tracking device in a vest on their back between the shoulder blades (JOHAN Sports) (Figure 2). The experimental statistics are shown in Table 2. The game took place on an outdoor grass field with a $60 \times 40 \mathrm{~m}$ pitch size (Figure 3). The corners and sidelines were marked with cones and a goal was placed at each side end of the field. One camera was positioned at the side of the field and one at the corner. The temperature on day 1 was $7^{\circ} \mathrm{C}$, with the relative humidity of $54 \%$. The temperature on day 2 was $6^{\circ} \mathrm{C}$, with the relative humidity of $87 \%$. Everyone performed $4 \times 4$-minute 5 vs. 5 SSGs, with 1-minute passive rest (standing still) and 1-minute active rest (walking) between the games (Table 2).

When the referee's whistle sounded, all the players stopped and stood still on the field. The RPE score was

Table 1. Subject characteristics on day 1 and day 2 of the test

\begin{tabular}{lcccccc} 
& $n$ & Age (years) & Height $(\mathrm{cm})$ & Weight $(\mathrm{kg})$ & HR $_{\max }(\mathrm{bpm})$ & \multicolumn{2}{c}{ Experience* $^{*}(\mathrm{years})$} \\
Junior & 14 & $17.6 \pm 0.5$ & $179.6 \pm 8.2$ & $69.6 \pm 8.6$ & $196.3 \pm 8.8$ & $6.5 \pm 1.8$ \\
Senior & $11^{* *}$ & $18.7 \pm 1.1$ & $178.1 \pm 6.6$ & $72.9 \pm 3.2$ & $197.3 \pm 7.2$ & $5.4 \pm 3.8$
\end{tabular}

$\mathrm{HR}_{\max }$ - maximum heart rate

* Years of professional experience at the current club

** There is a difference in the number of participants because more senior players participated on both days 

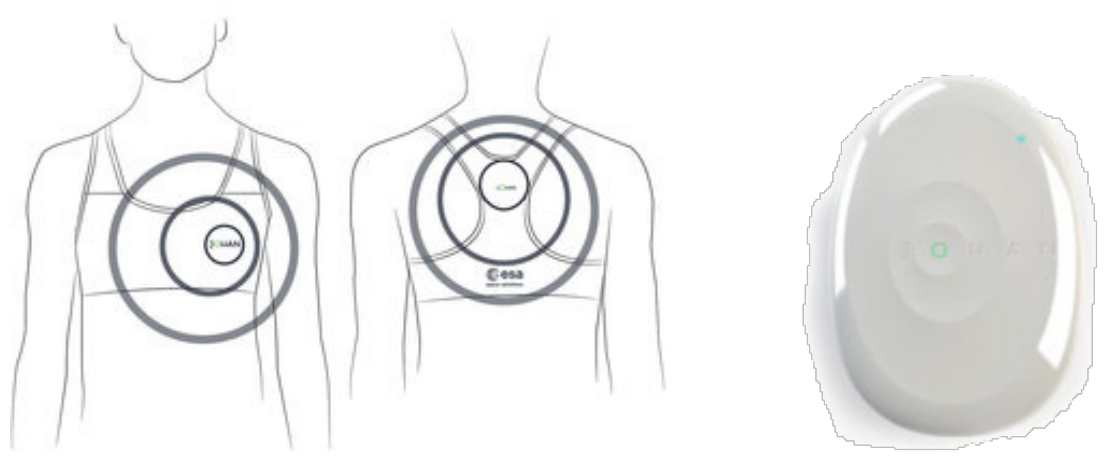

Figure 2. JOHAN vest, JOHAN sensor (copyright conceded by JOHAN Sports company)

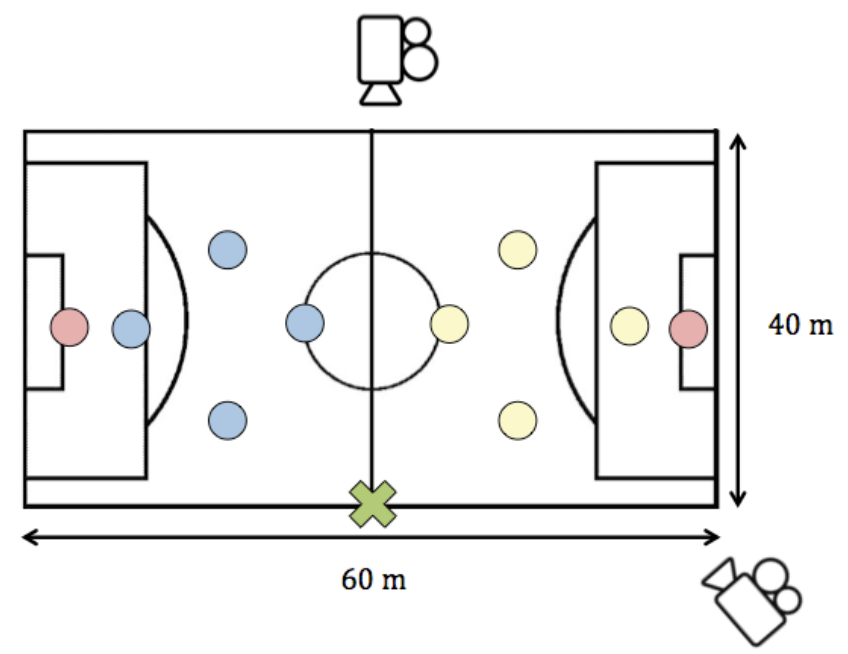

Figure 3. Measurement setup: position of the players and goalkeepers (circles), the coach (cross), and the cameras

Table 2. Experimental statistics

\begin{tabular}{cc} 
Game time & $4 \times 4$ minutes \\
Rest time & $\begin{array}{r}\text { 1-minute passive rest }+ \\
1 \text {-minute active rest }\end{array}$ \\
\hline $\begin{array}{c}\text { Pitch size } \mid \text { Pitch ratio } \\
\text { per player }\left(\mathrm{m}^{2}\right)\end{array}$ & $60 \times 40 \mathrm{~m} \mid 1: 240$ \\
\hline $\begin{array}{c}\text { Temperature day 1 } \\
\text { Humidity day 1 }\end{array}$ & $7^{\circ} \mathrm{C} \mid 54 \%$ \\
\hline $\begin{array}{c}\text { Temperature day 2 } \\
\text { Humidity day 2 }\end{array}$ & $6^{\circ} \mathrm{C} \mid 87 \%$ \\
\hline
\end{tabular}

noted in the first minute of rest after each 4-minute game. Keepers were restricted to hold the ball for a maximum of 3 seconds. If the ball went out of play, the game was restarted by the goalkeeper in the half in which the ball went out. Extra balls were placed in the goals to avoid long breaks during the game whenever the ball went out of play. In case of an injury, a reserve player was ready to step in so that the game could con- tinue. The data were only included when the subject played all $4 \times 4$-minute games. When players participated on both days, only the data from day 1 were included in the study, which allowed to avoid any influence of potential learning effects.

Time-motion measurement

The measurements were carried out with the JOHAN tracking system. It is a performance monitoring system, equipped with GPS $(10 \mathrm{~Hz}$, with SBAS correction) and IMU (100 Hz, 9-axis). According to literature, a $10-\mathrm{Hz}$ device is accurate enough to measure soccerspecific actions [13]. The following parameters were derived from the GPS: total distance, running distance (distance covered at $14-20 \mathrm{~km} / \mathrm{h}$ ), and sprint distance (distance covered at $>20 \mathrm{~km} / \mathrm{h}$ ). The acceleration sum parameter is derived from the IMU. Acceleration sum is the summation of accelerations in 3 directions (forward, sideward, upward) and can be calculated based on a previous study [22]:

\section{Heart rate measurement}

The heart rate was measured with the use of a shortrange telemetry system (Polar, Team2 Pro). The last peak in the heart rate data was applied to define the end of each 4-minute game because the heart rate was not synchronized with the JOHAN sensor. The mean heart rate of the last 30 seconds as a percentage of $\mathrm{HR}_{\text {max }}\left(\% \mathrm{HR}_{\text {mean }}\right)$ and time in seconds above $\mathrm{HR}_{\max } 90$ were used. Heart rate recovery, as well as the difference between the average heart rate of the last $30 \mathrm{sec}-$ onds of the 4-minute game and the heart rate at $60 \mathrm{sec}-$ onds after the end of the game (formula below) were also employed as an outcome measure.

$$
\text { HRrecovery }=\mid \text { HRmean }- \text { HR60sec,rest } \mid
$$




\section{HUMAN MOVEMENT}

L. Langendam, CMI (Niels) van der Linden, FM Clemente, Difference between age groups in soccer

\section{Rating of perceived exertion}

The CR10 scale by Foster et al. [23] was used (Table 3). All the players were familiar with the Borg scale and were asked the same standardized question: 'How hard was the SSG?' The participants were asked to point to the score on the Borg scale, and the other players could not copy the score. The RPE score was noted in 60 seconds after each 4-minute game.

The whole measurement was recorded with two digital video cameras (EOS 600D, Canon). The videos were played back and technical actions were derived from them and saved with the LongoMatch software. The 5 technical actions most important for determining intensity were used for the analysis (Table 4). The technical actions are precisely defined so that they were understandable for different raters. The number of technical actions per team was saved and the percentage of successful actions was calculated. Intra-rater reliability was calculated by analysing the game twice, by 2 different data analysts. Four random games were analysed by a second rater and the results were compared with those from the first rater.

The secondary outcome measurements were total distance $(\mathrm{m})$, velocity (distance travelled per minute $[\mathrm{m} / \mathrm{min}])$, distance covered during running $(14-20 \mathrm{~km} / \mathrm{h})$ and distance covered during sprint $(>20 \mathrm{~km} / \mathrm{h})$. These parameters were derived from the GPS in the JOHAN tracking system.

Table 3. Modified Borg scale CR10 for the rating of perceived exertion by Foster et al. [23]

\begin{tabular}{cc} 
Classification & Descriptor \\
\hline 0 & rest \\
\hline 1 & very, very easy \\
\hline 2 & easy \\
\hline 3 & moderate \\
\hline 4 & somewhat hard \\
\hline 5 & hard \\
\hline 6 & - \\
\hline 7 & very hard \\
\hline 8 & - \\
\hline 9 & maximum \\
\hline 10 & \\
\hline
\end{tabular}

Technical performance
Table 4. Definitions of technical actions during the game

\begin{tabular}{lc}
$\begin{array}{l}\text { Technical action } \\
\text { Dribble }\end{array}$ & $\begin{array}{c}\text { Definition } \\
\text { Interception }\end{array}$ \\
\hline Pass & $\begin{array}{r}\text { Preventing an opponent's pass } \\
\text { to another opponent }\end{array}$ \\
\hline Shot & Sending the ball to a team mate \\
\hline Tackle & Attempting to score \\
& $\begin{array}{c}\text { Obstructing an opponent to cause } \\
\text { loss of ball possession }\end{array}$
\end{tabular}

Additional parameters

Statistical procedures

First, the data were tested for normality with the Shapiro-Wilk normality test; homogeneity of variance was checked with the Levene's test before applying statistical methods. After normality was confirmed, a repeated measures ANOVA was used to compare the mean outcomes of the senior and junior players over the 4 consecutive games. SSGs were employed as the within-subject variable and the age groups as the between-subject variable. The level of significance was set at $p<0.05$. Cohen's $d$ was used as an effect size test for comparison between pairs. The following classification of magnitude of $d$ was applied [24]: no effect $(d<0.41)$, minimum effect $(0.41 \leq d<1.15)$, moderate effect $(1.15 \leqslant d<2.70)$, and strong effect $(d \geq$ 2.70). Bonferroni-corrected pairwise comparison served to find were the differences were between the games. The intra-class correlation coefficient (ICC) (two-way mixed, consistency) was calculated for the players who participated on both day 1 and day 2 of the test to check for reliability. The ICC (two-way mixed, absolute agreement) was also calculated for the intra-rater reliability. The confidence interval was set on $95 \%$. All data are presented as mean \pm standard deviation $(S D)$.

\section{Ethical approval}

The research related to human use has been complied with all the relevant national regulations, institutional policies and in accordance the tenets of the Helsinki Declaration, and has been approved by the authors' institutional review board or equivalent committee.

\section{RESULTS}

All the players were fit before the measurement and scored 8 or higher on the 0 -10-point VAS scale. 
The physiological responses for junior and senior players are presented per game (mean $\pm S D$ ). No differences were found in physiological responses between junior and senior players. Repeated measures ANOVA determined that all parameters, except running distance, differed statistically significantly across the games.

\section{5 vs. 5 SSG comparisons between teams}

The mean values and $S D$ s of all time-motion variables are displayed in Table 5. There was no significant effect of age groups over all SSGs: acceleration sum, $\mathrm{F}(1,15)=0.22, p=0.65, d=0.68$, minimum effect; RPE, $\mathrm{F}(1,15)=0.37, p=0.55, d=0.87$, minimum effect; running distance, $\mathrm{F}(1,15)=0.13, p=0.72, d=$ 0.76 , minimum effect; sprint distance, $\mathrm{F}(1,15)=1.71$, $p=0.211, d=2.57$, moderate effect.

\section{5 vs. 5 SSG comparisons across games}

A repeated measures ANOVA determined that the acceleration sum differed significantly across the games $\left(\mathrm{F}(3,45)=5.57, p<0.005, \eta p^{2}=0.27\right)$. Post-hoc tests with the Bonferroni correction revealed that the acceleration sum was higher in SSG 1 compared with SSG 3 and SSG 4.

RPE scores differed significantly across the games $\left(\mathrm{F}(3,51)=26.57, p<0.001, \eta p^{2}=0.61\right)$. Post-hoc tests with the Bonferroni correction revealed that RPE was lower in SSG 1 compared with SSG 2, 3, and 4, and RPE was higher in SSG 4 compared with SSG 1, 2, and 3.

Velocity differed significantly across the games $(\mathrm{F}(3,45)$ $=3.78, p<0.05, \eta p^{2}=0.20$ ). Post-hoc tests with the Bonferroni correction revealed that velocity was higher in SSG 1 and SSG 2 compared with SSG 3.

Repeated measures ANOVA with the GreenhouseGeisser correction determined that sprint distance differed significantly across the games $(\mathrm{F}(1.96,29.46)=$ 9.33, $p<0.001, \eta p^{2}=0.38$ ). Post-hoc tests with the Bonferroni correction revealed that sprint distance was higher in SSG 1 compared with SSG 2, and SD was lower in SSG 2 compared with SSG 3 and SSG 4.

\section{Heart rate}

Heart rate responses of junior $(n=3)$ and senior $(n=5)$ players are displayed in Figure 4 . There was no difference in $\% \mathrm{HR}_{\text {mean }}$ between junior players $(93.7 \pm$ $2.0 \%)$ and senior players (93.5 $\pm 3.9 \%)$. In addition, $\mathrm{HR}_{\max } 90$ also showed no difference between junior players (144 $\pm 74.8 \mathrm{~s})$ and senior players (148 $\pm 72.0 \mathrm{~s})$.
Table 5. Time-motion variables during 5 vs. 5 SSGs in junior and senior players (mean $\pm S D$ )

$$
\begin{array}{cc}
\text { Junior players } & \text { Senior players } \\
(n=10) & (n=7)
\end{array}
$$

SSG 1

\begin{tabular}{lcc} 
AS (au) & $31.8 \pm 4.4$ & $33.3 \pm 5.1$ \\
\hline RPE & $3.4 \pm 0.8$ & $3.3 \pm 1.8$ \\
\hline $\mathrm{V}(\mathrm{m} / \mathrm{min})$ & $133.1 \pm 14.1$ & $143.9 \pm 15.1$ \\
\hline $\mathrm{RD}(\mathrm{m})$ & $100.7 \pm 28.5$ & $110.4 \pm 31.7$ \\
\hline $\mathrm{SD}(\mathrm{m})$ & $16.2 \pm 11.4$ & $21.9 \pm 14.6$
\end{tabular}

SSG 2

\begin{tabular}{lcc} 
AS (au) & $32.5 \pm 4.9$ & $31.1 \pm 4.6$ \\
\hline $\mathrm{RPE}$ & $4.3 \pm 0.6$ & $4.3 \pm 1.7$ \\
\hline $\mathrm{V}(\mathrm{m} / \mathrm{min})$ & $136.6 \pm 12.0$ & $138.2 \pm 14.6$ \\
\hline $\mathrm{RD}(\mathrm{m})$ & $109.3 \pm 36.0$ & $108.7 \pm 34.3$ \\
$\mathrm{SD}(\mathrm{m})$ & $2.2 \pm 3.8$ & $4.3 \pm 6.8$
\end{tabular}

SSG 3

\begin{tabular}{lcc} 
AS (au) & $31.6 \pm 5.5$ & $28.7 \pm 4.7$ \\
\hline RPE & $4.8 \pm 1.0$ & $4.3 \pm 1.9$ \\
\hline $\mathrm{V}(\mathrm{m} / \mathrm{min})$ & $133.1 \pm 12.4$ & $126.3 \pm 13.5$ \\
\hline $\mathrm{RD}(\mathrm{m})$ & $88.4 \pm 28.6$ & $84.6 \pm 43.4$ \\
\hline $\mathrm{SD}(\mathrm{m})$ & $15.4 \pm 12.9$ & $15.1 \pm 10.0$
\end{tabular}

SSG 4

\begin{tabular}{lcc} 
AS (au) & $31.2 \pm 4.0$ & $29.9 \pm 4.5$ \\
\hline RPE & $5.7 \pm 1.1$ & $4.7 \pm 2.0$ \\
\hline $\mathrm{V}(\mathrm{m} / \mathrm{min})$ & $133.4 \pm 11.7$ & $136.0 \pm 14.4$ \\
\hline $\mathrm{RD}(\mathrm{m})$ & $96.6 \pm 17.8$ & $110.1 \pm 29.8$ \\
\hline $\mathrm{SD}(\mathrm{m})$ & $25.7 \pm 19.6$ & $25.1 \pm 14.1$
\end{tabular}

SSG - small-sided game, AS - acceleration sum,

$\mathrm{RPE}$ - rating of perceived exertion, $\mathrm{V}$ - velocity,

$\mathrm{RD}$ - running distance (at $14-20 \mathrm{~km} / \mathrm{h}$ ),

SD - sprint distance (at $>20 \mathrm{~km} / \mathrm{h}$ )

Heart rate recovery was lower in junior players (31 \pm $3.9 \mathrm{bpm}$ ) compared with senior players (43 $\pm 3.4 \mathrm{bpm})$.

Technical actions

The technical actions of all players on day 1 (Figures 5,6) and day 2 were analysed. No significant difference was found between juniors and seniors in the number of technical actions. The percentage of successful passes and shots for day 1 and day 2 are 


\section{HUMAN MOVEMENT}

L. Langendam, CMI (Niels) van der Linden, FM Clemente, Difference between age groups in soccer

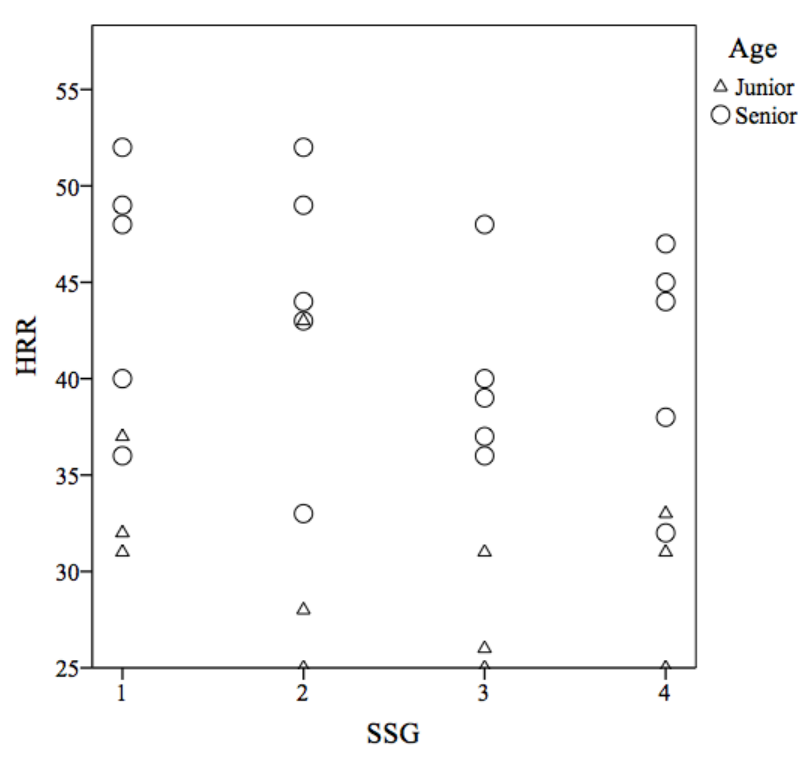

HRR - heart rate recovery, SSG - small-sided game

Figure 4. Heart rate response of junior (triangles) and senior (circles) players during all 4 SSGs



SSG - small-sided game

Figure 5. Technical actions during 5 vs. 5 SSG in junior players on day 1; 95\% confidence interval

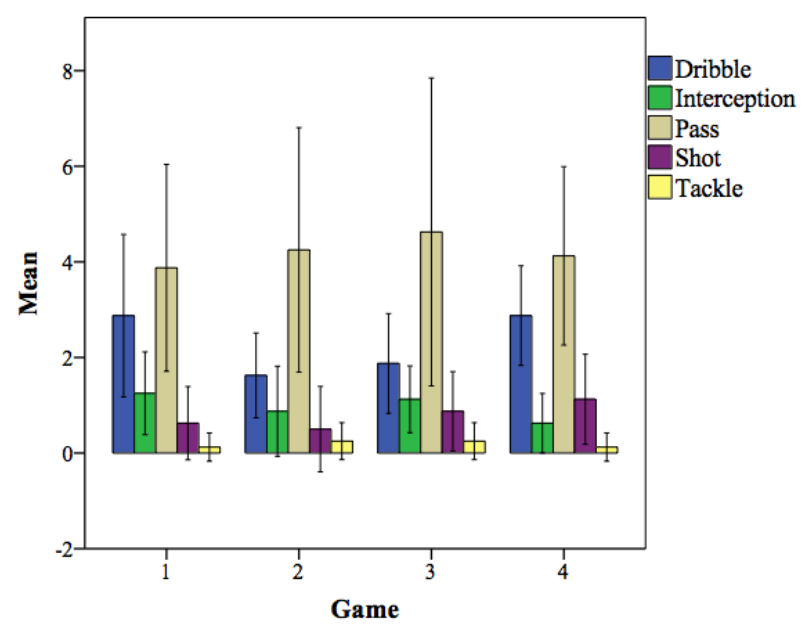

Figure 6. Technical actions during 5 vs. 5 SSG in senior players on day 1; 95\% confidence interval
Table 6. Percentage of successful technical actions of day 1 and day 2 per age category

$$
\text { Junior }(n=8) \quad \text { Senior }(n=8)
$$

Day 1

\begin{tabular}{lcc}
\hline Passes $(n)$ & 152 & 143 \\
\hline Successful passes (\%) & 86 & 85 \\
\hline Shots $(n)$ & 27 & 26 \\
\hline Successful shots (\%) & 34 & 17 \\
\hline Day 2 & & \\
\hline Passes $(n)$ & 143 & 142 \\
\hline Successful passes (\%) & 84 & 87 \\
\hline Shots $(n)$ & 23 & 25 \\
\hline Successful shots $(\%)$ & 47 & 17
\end{tabular}

shown in Table 6. The percentage of successful passes was almost the same for junior and senior players on both days. The percentage of successful shots was much higher for juniors on both days.

\section{5 vs. 5 SSG reliability}

The test-retest reliability was calculated with the ICC for the 8 subjects who participated on day 1 and day 2 of the test (Table 7). The RPE score (0.88) and acceleration sum (0.75) showed high ICC values. The running distance $(0.41)$ presented an average ICC value. Velocity (0.29) and sprint distance (0.09) were bound with very low values.

The mean ICCs of the 4 randomly chosen games are presented in Table 8 . The intra-rater reliability of all the technical actions was higher than 0.88 , which means good reliability.

Pearson product-moment correlation was calculated to determine the relationship between acceleration sum and total distance. There was a strong positive correlation between these parameters, which turned out statistically significant $(r=0.813, n=17, p<$ 0.001), as seen in Figure 7.

\section{DISCUSSION}

This research focused on physiological responses (heart rate, $\mathrm{RPE}$ ), time-motion variables (acceleration sum, distance covered), and technical actions (dribble, interception, pass, shot, tackle) across SSGs in junior and senior soccer players. We found no differences in time-motion variables or technical actions between 
Table 7. Intra-class correlation coefficient of 5 vs. 5 SSG time-motion and physiological responses

\begin{tabular}{lc}
$n=8$ & ICC $(95 \% \mathrm{CI})$ \\
$\mathrm{AS}(\mathrm{au})$ & 0.75 (from -0.24 to 0.95$)$ \\
\hline $\mathrm{RPE}$ & 0.88 (from 0.42 to 0.98$)$ \\
\hline $\mathrm{V}(\mathrm{m} / \mathrm{min})$ & 0.29 (from -2.67 to 0.86$)$ \\
\hline $\mathrm{RD}(\mathrm{m})$ & 0.41 (from -1.94 to 0.88$)$ \\
\hline $\mathrm{SD}(\mathrm{m})$ & 0.09 (from -4.46 to 0.78$)$
\end{tabular}

SSG - small-sided game, ICC - intra-class correlation coefficient, CI - confidence interval, AS - acceleration sum, RPE - rating of perceived exertion, $\mathrm{V}$ - velocity, $\mathrm{RD}$ - running distance (at $14-20 \mathrm{~km} / \mathrm{h}$ ),

$\mathrm{SD}$ - sprint distance (at $>20 \mathrm{~km} / \mathrm{h})$

Table 8. Intra-class correlation coefficient (ICC) of the intra-rater reliability

\begin{tabular}{ll}
$n=8$ & \multicolumn{1}{c}{ ICC $(95 \% \mathrm{CI})$} \\
\begin{tabular}{l} 
Dribble \\
\hline Interception
\end{tabular} & 0.92 (from -0.27 to 0.99$)$ \\
\hline Pass & 0.88 (from -0.15 to 0.95$)$ \\
\hline Shot & 0.97 (from 0.56 to 0.99$)$ \\
\hline Tackle & 0.97 (from 0.67 to 0.99$)$ \\
\hline Re & 0.89 (from -0.12 to 0.99$)$
\end{tabular}

Relationship of the acceleration sum and total distance

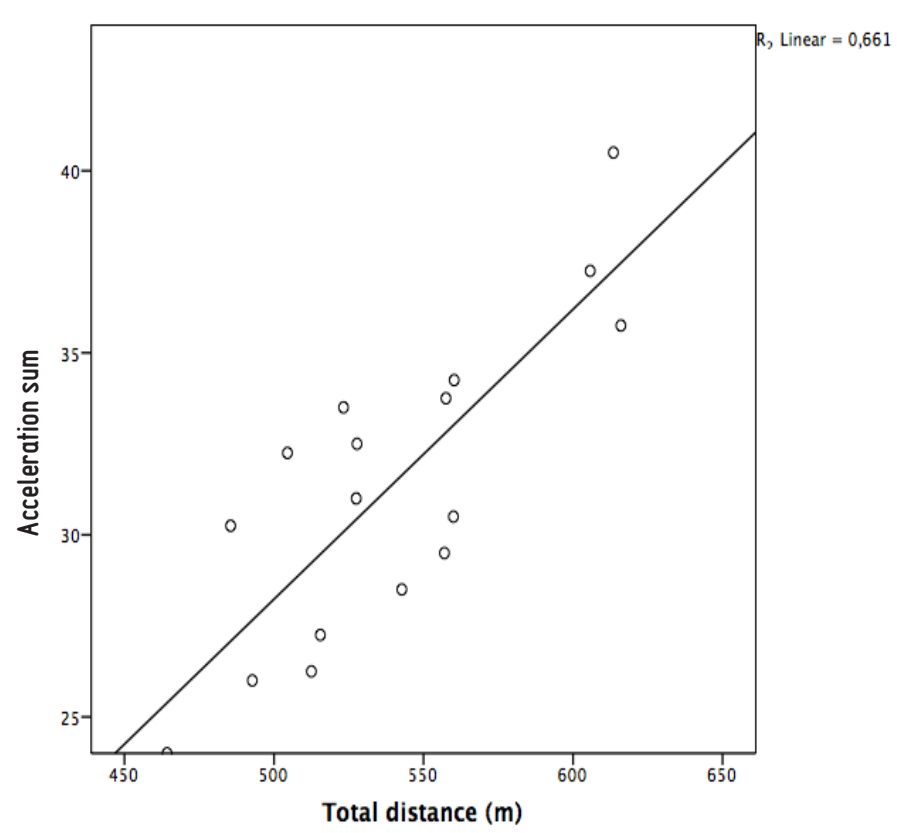

Figure 7. Correlation between the acceleration sum and total distance, best fitted line: $\mathrm{R}_{\text {Linear }}^{2}=0.661$,

$$
y=-11.57+0.08^{*} x
$$

junior and senior players. Heart rate measurements $\left(\% \mathrm{HR}_{\text {mean }}, \mathrm{HR}_{\max } 90\right)$ also did not differ between junior and senior players, except for the heart rate recovery. In addition, the acceleration sum stayed the same for both age groups - across the games, but the RPE scores increased. The heart rate recovery showed a slight decrease across the games, which suggests that the players were still not fully recovered. Furthermore, the number of technical actions was the same for both age groups, in contrast with the percentage of successful passes and shots, which was higher in the group of junior players. Finally, the number of technical actions across the games did not change, either.

These findings were in agreement with a study by Stevens et al. [12], who found no differences in total distance and velocity between professional youth players (17 \pm 1 years) and professional senior players (21 \pm 3 years) in 6 vs. 6 SSGs. Besides, they observed a higher $\% \mathrm{HR}_{\text {mean }}$ in youth soccer players. However, this may be explained by higher RPE scores (5.3-7.6) in the mentioned study, which suggests that SSGs were more fatiguing than in our study (3.3-5.7). Another reason could be the small difference in age between young (17.6 \pm 0.5 years) and senior $(18.7 \pm 1.1$ years $)$ players in our study.

Additionally, in a study by Köklü et al. [17], the $\% \mathrm{HR}_{\text {mean }}$ was between $80.9-93.4 \%$ during $6 \times 4$-minute 4 vs. 4 SSGs, which is similar to the numbers that we found. These high percentages imply the SSGs to be challenging enough for training to increase maximal oxygen uptake. Stevens et al. [12] found lower heart rates in senior players $(171 \pm 7 \mathrm{bpm})$, which they explained with the ceiling effect caused by the restrictions of the game. In contrast, heart rates of junior and senior players were similar to those in our study. The heart rate recovery turned out lower the junior players, indicating that the game was more exhausting for them. It could be expected that the acceleration sum or number of technical actions would decrease owing to fatigue. Unfortunately, only the data of 3 junior players were captured. These participants may be less fit than the others, which would strongly influence the outcomes.

In another study, Kelly and Drust [19] showed that heart rate increased over the interval bouts. This is different from our results, where the heart rate stayed steady across the games. The recovery time was the same in both studies, but in our study the first minute was passive rest (no talking or moving). When the timemotion variables stay the same across the games, it would be expected that the heart rate increased because of fatigue. 
L. Langendam, CMI (Niels) van der Linden, FM Clemente, Difference between age groups in soccer

Apart from the physiological responses and timemotion variables, technical actions can influence the game intensity. The number of technical actions did not change across the games. In contrast, the number of technical actions decreased in a study by Kelly and Drust [19], which could be a consequence of fatigue. This suggests that the SSGs in this study were less fatiguing, and this was confirmed by the physiological responses staying steady. It was surprising that the junior players had a higher percentage of successful passes and shots compared with the seniors. The expectation could be that older players have more experience, but the years of experience at the current club was higher in junior players $(6.5 \pm 1.8)$ than in seniors $(5.4 \pm 3.8)$. Maybe tactical aspects play a role, for example, when the defending team applies high pressure to win the ball. When this is more present in the senior team, it will make it harder to successfully pass or shoot. Another explanation could be that the keepers of the senior team were more successful, which would make it harder for the players to score.

Another finding in this study was the high correlation between total distance and the acceleration sum, also observed in other studies $[8,10]$. This indicates that the acceleration sum does not seem to bring any new information for coaches when compared with total distance. The acceleration sum can be defined as the summation of accelerations in 3 directions and is a new parameter in the research of sports. This takes the different movements during football into account, like jumping, diving, and sideward actions. Thus the acceleration sum would add valuable information to the training intensity. The high correlation with total distance shows that the importance of the acceleration sum is overrated and total distance alone could give a good indication of the physical activity. More research is necessary to investigate the advantage of using the acceleration sum instead of distance covered. It would be interesting to examine other types of SSGs, other field dimensions, and other rules.

Although SSGs allow to easily test physiological responses and time-motion variables during training and can be well standardized, it is still not clear whether they can be used to detect differences between age groups. Some limitations may clarify the absence of differences between age groups. First, there was a small difference in age between juniors (17.6 \pm 0.5 years) and senior players (18.7 \pm 1.1 years), and the amount of training hours per week was similar. Second, the small number of participants (juniors, $n=14$; seniors, $n=11$ ) made it difficult to draw any conclusions. Especially the heart rate measurements were performed among small groups (juniors, $n=3$; seniors, $n=5$ ) owing to loss of data, but the results do not suggest that there would be any differences with more participants. Third, the combination of decreasing heart rate recovery and increasing RPE across the games indicates that the players were not fully recovered after 2 minutes of rest. This may affect the junior players more than the senior players, as the training status of the former is lower. If the rest between the games had been longer, the timemotion variables (such as the acceleration sum, velocity, running distance, and sprint distance) might have been higher for some junior players. If there had been a ceiling effect, the senior players would not have shown higher values with more rest between the games. Finally, the last limitation of the study is the switch in players during the season, which affected the number of participants on day 2 since players were only included in the study when participating for the first time. However, all athletes were familiar with 5 vs. 5 SSGs and therefore any learning effect would not change the results.

SSGs are easy to standardize and are often used in training sessions. It saves a lot of time and testing when a trainer can apply the physiological data from the training to check whether his players improve. There appears to be no difference between junior (playing in the First Division for junior players) and senior players (playing in the Third Division), which indicates that the juniors are capable to play with the seniors. This will provide a better flow of talented junior players to the senior team.

In further research, it might be interesting to focus on the tactical actions between the age groups since the surprising outcome of our study was a higher percentage of successful actions in junior players. This difference may be caused by the goalkeepers being more efficient in the senior team or by the difference in tactical actions. If the senior team had played more aggressively, the number of passes and shots could have been bigger, but the number of misses would have also been higher.

\section{CONCLUSIONS}

The study determined whether there were any differences in physiological responses, time-motion variables, or technical actions between junior and senior players and across the games during 5 vs. 5 SSGs. No differences were found between the two age groups in the acceleration sum, RPE, velocity, or distance covered. The heart rate recovery was lower among junior players, but the number of participants here was not enough to draw any binding conclusions. The small difference in 
age and the amount of training hours between junior and senior players makes it difficult to investigate any differences. Surprisingly, the percentage of successful actions in junior players was higher compared with seniors. Further research could focus on tactical actions to explore the difference in strategy, which may explain the difference in success. The physiological responses varied across the games, but no linear increase or decrease was observed except for the RPE scores, which increased slightly for all players across the games owing to fatigue. Altogether, we can accept our hypothesis and conclude that physiological responses and technical actions do not differ between junior and senior soccer players. The results of this experiment show that the junior players at this particular club are physically capable of playing in the senior team.

\section{Disclosure statement}

No author has any financial interest or received any financial benefit from this research.

\section{Conflict of interest}

Authors state no conflict of interest.

\section{References}

1. Brink M, Nederhof E, Visscher C, Schmikli SL, Lemmink K. Monitoring load, recovery, and performance in young elite soccer players. J Strength Cond Res. 2010; 24(3):597-603; doi: 10.1519/JSC.0b013e3181c4d38b.

2. Henderson B, Cook J, Kidgell DJ, Gastin PB. Game and training load differences in elite junior Australian football. J Sports Sci Med. 2015;14(3):494-500.

3. Impellizzeri FM, Rampinini E, Coutts AJ, Sassi A, Marcora SM. Use of RPE-based training load in soccer. Med Sci Sports Exerc. 2004;36(6):1042-1047; doi: 10.1249/01.MSS.0000128199.23901.2F.

4. Scott BR, Lockie RG, Knight TJ, Clark AC, Janse de Jonge XAK. A comparison of methods to quantify the in-season training load of professional soccer players. Int J Sports Physiol Perform. 2013;8(2):195-202; doi: 10.1123/ijspp.8.2.195.

5. Buchheit M, Simpson MB, Al Haddad H, Bourdon PC, Mendez-Villanueva A. Monitoring changes in physical performance with heart rate measures in young soccer players. Eur J Appl Physiol. 2012;112(2):711-723; doi: 10.1007/s00421-011-2014-0.

6. Foster CD, Twist C, Lamb KL, Nicholas CW. Heart rate responses to small-sided games among elite junior rugby league players. J Strength Cond Res. 2010;24(4): 906-911; doi: 10.1519/JSC.0b013e3181aeb11a.

7. Hoff J, Wisløff U, Engen LC, Kemi OJ, Helgerud J. Soccer specific aerobic endurance training. Br J Sports Med. 2002;36(3):218-221; doi: 10.1136/bjsm.36.3.218.

8. Barron DJ, Atkins S, Edmundson C, Fewtrell D. Accelerometer derived load according to playing position in competitive youth soccer. Int J Perform Anal Sport. 2014;14(3):734-743; doi: 10.1080/24748668.2014. 11868754.

9. Cummins C, Orr R, O’Connor H, West C. Global positioning systems (GPS) and microtechnology sensors in team sports: a systematic review. Sports Med. 2013; 43(10):1025-1042; doi: 10.1007/s40279-013-0069-2.

10. Casamichana D, Castellano J, Calleja-Gonzalez J, San Román J, Castagna C. Relationship between indicators of training load in soccer players. J Strength Cond Res. 2013;27(2):369-374; doi: 10.1519/JSC.0b013e 3182548 af1.

11. Dellal A, Hill-Haas S, Lago-Penas C, Chamari K. Smallsided games in soccer: amateur vs. professional players' physiological responses, physical, and technical activities. J Strength Cond Res. 2011;25(9):2371-2381; doi: 10.1519/JSC.0b013e3181fb4296.

12. Stevens TG, De Ruiter CJ, Beek PJ, Savelsbergh GJ. Validity and reliability of 6-a-side small-sided game locomotor performance in assessing physical fitness in football players. J Sports Sci. 2016;34(6):527-534; doi: 10.1080/02640414.2015.1116709.

13. Johnston RJ, Watsford ML, Kelly SJ, Pine MJ, Spurrs RW. Validity and interunit reliability of $10 \mathrm{~Hz}$ and $15 \mathrm{~Hz}$ GPS units for assessing athlete movement demands. J Strength Cond Res. 2014;28(6):1649-1655; doi: 10.1519/ JSC.0000000000000323.

14. Dellal A, Chamari K, Pintus A, Girard O, Cotte T, Keller D. Heart rate responses during small-sided games and short intermittent running training in elite soccer players: a comparative study. J Strength Cond Res. 2008; 22(5):1449-1457; doi: 10.1519/JSC.0b013e31817398c6.

15. Aguiar M, Botelho G, Lago C, Maças V, Sampaio J. A review on the effects of soccer small-sided games. J Hum Kinet. 2012;33:103-113; doi: 10.2478/v10078-0120049-x.

16. Rampinini E, Impellizzeri FM, Castagna C, Abt G, Chamari K, Sassi A, et al. Factors influencing physiological responses to small-sided soccer games. J Sports Sci. 2007;25(6):659-666; doi: 10.1080/02640410600811858.

17. Köklü Y, Aşçi A, Koçak FU, Alemdaroğlu U, Dündar U. Comparison of the physiological responses to different small-sided games in elite young soccer players. J Strength Cond Res. 2011;25(6):1522-1528; doi: 10.1519/JSC. 0b013e3181e06ee1.

18. Hodgson C, Akenhead R, Thomas K. Time-motion analysis of acceleration demands of $4 \mathrm{v} 4$ small-sided soccer games played on different pitch sizes. Hum Mov Sci. 2014;33:25-32; doi: 10.1016/j.humov.2013.12.002.

19. Kelly DM, Drust B. The effect of pitch dimensions on heart rate responses and technical demands of smallsided soccer games in elite players. J Sci Med Sport. 2009;12(4):475-479; doi: 10.1016/j.jsams.2008.01.010.

20. Fanchini M, Azzalin A, Castagna C, Schena F, McCall A, Impellizzeri FM. Effect of bout duration on exercise intensity and technical performance of small-sided games in soccer. J Strength Cond Res. 2011;25(2):453458; doi: 10.1519/JSC.0b013e3181c1f8a2. 


\section{HUMAN MOVEMENT}

L. Langendam, CMI (Niels) van der Linden, FM Clemente, Difference between age groups in soccer

21. Di Salvo V, Benito PJ, Calderón FJ, Di Salvo M, Pigozzi F. Activity profile of elite goalkeepers during football matchplay. J Sports Med Phys Fitness. 2008;48(4):443-446.

22. Casamichana D, Castellano J, Calleja-Gonzalez J, San Román J, Castagna C. Relationship between indicators of training load in soccer players. The Journal of Strength \& Conditioning Research. 2013;27(2):369-374, doi: 10.1519/JSC.0b013e3182548af1.

23. Foster C, Florhaug JA, Franklin J, Gottschall L, Hrovatin LA, Parker S, et al. A new approach to monitoring exercise training. J Strength Cond Res. 2001;15(1):109115; doi: 10.1519/00124278-200102000-00019.

24. Ferguson CJ. An effect size primer: a guide for clinicians and researchers. Prof Psychol Res Pract. 2009;40(5): 532-538; doi: 10.1037/a0015808. 